\title{
EDITORIAL
}

\section{As redes sociais aplicadas ao turismo e à hotelaria}

\section{Social media applied to tourism and hospitality}

A sociedade atual é caracterizada pela criatividade e inovação, quer nos modelos de negócio quer na tecnologia, e também pela crescente digitalização e reengenharia dos seus processos. Este ambiente digital promove novas formas de complexidade e de conhecimento em diversas áreas da sociedade e em diversos setores de atividade económica, como na gestão, hotelaria, marketing, turismo, entre outros.

Neste contexto, as redes sociais são uma destas tecnologias emergentes e têm um impacto substancial na indústria do turismo, em geral, e na hospitalidade, em particular, bem como no marketing e na forma como as organizações passaram a comunicar.

Atualmente, os turistas utilizam frequentemente as redes sociais para procurar e partilhar informações sobre um produto ou destino turístico, promovendo assim a criação de ferramentas de apoio às suas decisões, e contribuindo para o desenvolvimento destas plataformas, também, como agências de turismo. Neste ambiente digital, os turistas partilham, como dissemos, as suas experiências de viagem, impressões, emoções, momentos especiais e opiniões sobre os serviços turísticos, nomeadamente, hotéis, restaurantes, companhias aéreas, serviços de aluguer de automóveis, eventos ou serviços auxiliares, os quais contribuem para definir a reputação online de um destino turístico e das suas organizações.

A investigação académica pode oferecer contributos importantes sobre as redes sociais, nomeadamente, sobre, temas associados aos conteúdos gerados pelos utilizadores (user generator content), estratégias para dispositivos móveis, análises das redes sociais, entre outros.

É neste sentido que surge este número especial da revista Dos Algarves: A Multidisciplinary e-Journal dedicado às redes sociais aplicadas ao turismo e à hotelaria, cujo objetivo é contribuir para a construção e divulgação do conhecimento nesta área científica, bem como para ajudar a revelar novos caminhos de investigação nesta área e em áreas afins. Neste número publicamos sete artigos escritos em português, espanhol e inglês sobre as potencialidades das social media no contexto do turismo, da hotelaria, do marketing e da gestão.

Dos Algarves: A Multidisciplinary e-Journal, $32-2018$.

ISBN 2182-5580 @ ESGHT - University of the Algarve, Portugal.

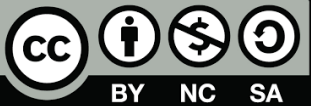


Na área do turismo, as redes sociais são uma plataforma privilegiada de comunicação entre as empresas e os consumidores, por exemplo, através do user generated content (UGC) o que pode contribuir para a compreensão da relação existente entre o valor funcional e a utilidade percebida pelos consumidores em relação a estes conteúdos disponibilizados no Youtube. As redes sociais podem igualmente ser um meio para identificar e caracterizar padrões de comportamento dos turistas nestas plataformas durante e após as suas viagens, averiguando o que os leva a gerar conteúdos nestes novos meios de comunicação.

$\mathrm{Na}$ área da hotelaria e da restauração, o surgimento de novas ferramentas online permite analisar as avaliações de clientes sobre restaurantes, nas quais os atributos "comida" e "serviço" se destacam ao revelar uma maior correlação com a satisfação dos clientes. Neste contexto, as mensagens instantâneas (MI) têm contribuído para a implementação de chatbots nestes canais, com o fim de ajudar no planeamento do consumo gastronómico, bem como para a análise da presença do setor hoteleiro nas redes sociais em comparação com os outros setores económicos.

No marketing, uma das principais potencialidades das redes sociais é o facto de serem poderosas plataformas de relacionamento, captação e fidelização de clientes, bem como têm o potencial de influenciar novos comportamentos do consumidor, obrigando à definição de novas estratégias e ferramentas de comunicação dos destinos turísticos. Adicionalmente, as redes sociais contribuem para a partilha de experiências de lazer, para criar proximidades e contrariar a padronização, potenciando o desenvolvimento de um turismo de afinidades e de um turismo de experiências, o que concorre para a criação de memórias e para o aumento do valor dos momentos de lazer e de consumo.

Por fim, manifestamos o agradecimento a todos os que contribuíram para a concretização deste número especial da revista Dos Algarves: A Multidisciplinary e-Journal, e esperamos contribuir para a descoberta de novos caminhos de investigação.

Os editores convidados

Célia M.Q. Ramos Escola Superior de Gestão, Hotelaria e Turismo da Universidade do Algarve, Portugal Carlos M. R. Sousa Escola Superior de Gestão, Hotelaria e Turismo da Universidade do Algarve, Portugal Ana Maria Casado-Molina Departamento de Economía y Administración de Empresas de la Universidad de Málaga, Espanha 